\title{
As santinhas de cemitério que fazem milagres: um estudo comparado das devoções de "Mariazinha" Penna e Maria Elizabeth de Oliveira
}

The miraculous cemetery saints: a comparative study of the devotions of "Mariazinha" Penna and Maria Elizabeth de Oliveira

Franciele Moreira Cassol* fran_cassol@yahoo.com.br

Resumo: Mesmo com as conquistas da ciência moderna, a religiosidade permanece presente e se afirma a cada dia como forma de explicar e vivenciar o sobrenatural para significativa parcela da população brasileira. Essa permanência revela-se na trajetória do catolicismo e nas articulações dos ritos e práticas litúrgicas e fazem surgir diferentes modalidades de convivência com o sagrado e modos peculiares de vivenciar a espiritualidade. Nesse sentido, a presente pesquisa almeja discutir e analisar em um primeiro momento a construção hagiográfica das devoções populares nas biografias, bem como, em um segundo momento a publicização dessas devoções a "Mariazinha" Penna (Santa Maria/RS) e Maria Elizabeth de Oliveira (Passo Fundo/RS), a partir dos jornais locais "A Razão" e "O Nacional". As devoções que são manifestadas perante os túmulos das "santinhas" dos cemitérios demonstram uma prática de fé. São pessoas comuns/jovens que, após a morte, ganharam a veneração de fieis que lhes pedem auxílio junto ao sagrado, e que são cultuadas como milagreiras em suas cidades natais. "Mariazinha" por ser exemplo de resignação e força diante uma doença e, Maria Elizabeth por realizar previsões sobre a sua própria morte.

Palavras-chave: devoções, turismo, comércio

Abstract: Even with the achievements of modern science, religion remains present and affirms every day as a way to explain and experience the supernatural to a significant portion of the population. This permanence is revealed in the course of Catholicism and in the joints of liturgical rites and practices and give rise to different ways of living with the sacred and peculiar ways of experiencing spirituality. In this sense, this research aims to discuss and analyze at first the hagiographic construction of popular devotions in the biographies as well, in a second time the popularization of these devotions to Gretel"Penna (Santa Maria / RS) and Mary Elizabeth de Oliveira (Passo Fundo / RS), from the local newspaper the Reason"and the National.'Devotions that are manifested before the tombs of Santinhas"cemeteries demonstrate a practice of faith. Are ordinary people / young people who, after death, won the veneration of the faithful who ask for assistance from the sacred, and are worshiped as milagreiras in their hometowns. Gretel'by being an example of resignation and strength before an illness and Mary Elizabeth for making predictions about his own death.

Keywords: devotions, tourism, trade

*Doutoranda em História pela Universidade de Passo Fundo/RS. 


\section{Introdução}

O campo das religiosidades atual e das devoções populares as "santas locais" é parte de um processo amplo, longo e complexo, que tem de levar em consideração o latente pluralismo religioso, bem como, o processo de modernidade vinculado ao processo de secularização da sociedade, visto que, após esse processo, tanto a fé quanto as práticas religiosas entraram em declínio. A princípio parece que a secularização teria como consequência: a racionalidade do homem e a "evolução" da sociedade. Nesse contexto, a crítica às religiões (sejam estas católicas, espíritas, afrobrasileiras, etc.), como um todo, se encontrariam no fato de que estas seriam desprovidas de racionalidade, de coerência interna em seu sistema de pensamento, mas, por outro lado, é notável que as diferentes tradições religiosas encontram-se em permanente processo de reinvenção e rearticulação. No entanto, defendemos o estudo das devoções e dos rituais intrínsecos a estas, por acreditar que o pensamento do devoto em relação a seu santo protetor, até pode ser mítico, mas também é ao mesmo tempo coerente e obediente a sua própria lógica; e que atualmente pode estar sincretizado com práticas de comércio, mercado e turismo ${ }^{1}$. Além disso, devemos compreender as consequências do processo de secularização na sociedade brasileira, pois este tende a questionar a natureza e o próprio lugar do sagrado nas sociedades contemporâneas. Não obstante, objetivamos neste, evitar a visão de cultura que entende a religiosidade das pessoas e seu pensamento "místico, mágico ou religioso" como algo arcaico e retrógrado, posto o ideal de sociedade avançada, racional e moderna. E nesse contexto, perceber que a migração do sagrado para o profano, ou do campo do religioso para o turístico é um processo comumente encontrado nas culturas e nas devoções populares contemporâneas.

\section{Do bem simbólico que são as devoções}

Maria Elizabeth de Oliveira nasceu na cidade de Passo Fundo, no dia 6 de fevereiro de 1951. Entretanto, seus pais, Leda de Oliveira e Alcides de Oliveira eram naturais do município de Lagoa Vermelha. Em função dos estudos Maria Elizabeth veio morar em Passo Fundo com seus avós, tendo estudado no Ginásio Menino Jesus e mais tarde no Grupo Escolar Protásio Alves. A breve vida de Maria Elizabeth segundo registros (FANIANI, 2006), destacou-se, entre outros, por participar de modo intenso da vida religiosa citadina e da moral pregada pelo catolicismo, visto que, além de participar de coral religioso, também auxiliava os padres, na Igreja Matriz Santa Terezinha.

Em 1965 ano de seu falecimento, também os pais de Maria Elizabeth mudaram para a cidade, vindo a residir na Avenida Presidente Vargas, avenida esta que viria a ser o lugar onde a menina sofreria um acidente em 28 de novembro daquele ano. No dia de sua morte, Maria Elizabeth encontrava-se com um grupo de amigas, na esquina das ruas Padre Valentin com a Avenida Presidente Vargas, quando em torno das $15 \mathrm{hs}$ de um domingo, uma Kombi, dirigida por Gentil Lima subiu a calçada desgovernadamente, atropelando o grupo de jovens que ali se encontravam. Maria Elizabeth chegou a ser levada ao hospital local São Vicente de Paulo demonstrado em seu corpo externamente apenas um ferimento no pé, todavia, internamente a mesma encontrava-se com uma séria hemorragia, que a

\footnotetext{
${ }^{1}$ Entendemos o turismo como sendo o conjunto de atividades realizadas pelos indivíduos durante as suas viagens e estadias em lugares diferentes daqueles do seu entorno habitual por um período de tempo. Em grande parte das vezes, a atividade turística é realizada com o objetivo do lazer, embora também exista o turismo por razões de negócios. O turismo, tal como compreendemos hoje, nasceu no século XIX, na sequência da Revolução Industrial, que possibilitou as deslocações tendo por função o descanso ou ainda motivos sociais ou culturais. Entretanto, mesmo antes, ou já na antiguidade podemos supor a existência de um tipo de turismo, ou seja, a partir das viagens, ou peregrinações a lugares santos, entre outros.
} 
levou a morte (FABIANI, 2006; ZANELLA, 1997; BARBOSA, 2014; ACOSTA, 2009; MORENNO, 1994).

A morte brusca de uma jovem passo-fundense, com menos de quinze anos, segundo os jornais e pessoas contemporâneas ao fato relatam que este acidente chocou a cidade inteira. Logo após o ocorrido, a história de que Maria Elizabeth de Oliveira havia previsto sua própria morte, escolhido seu caixão e a roupa que "usaria por toda a eternidade" e a aceitado abnegadamente espalhou-se rapidamente (FABIANI, 2006; ZANELLA, 1997; BARBOSA, 2014; ACOSTA, 2009; MORENNO, 1994).

Já na biografia escrita em 1988 sobre a "santinha" santa-mariense - Mariazinha Penna, a autora desta destaca a personalidade e as qualidades da biografada enquanto viva como o mote central de motivação ao leitor (e futuro fiel) a conhecer sua história. O livro, "Mariazinha Penna - a predestinada", Abelin reconstitui a vida da santa popular santa-mariense por meio de entrevistas com cerca de 250 fieis, mas também, com pessoas próximas da mesma, incluindo sua mãe - Aida Penna, vizinhos e até mesmo um pároco. A partir do livro, podemos entender parte da devoção a Mariazinha, visto que, a autora salienta a postura de vida singular da "santinha" enquanto viva, evidenciando o final da doença em que a mesma, além de aceitar seu fim fatídico ("uma heroína na dor"), também confortava seus amigos e familiares a respeito de sua dor e consequente morte. Dizem os relatos ${ }^{2}$, que a moça recebia os visitantes sempre com "um sorriso no rosto"; que sempre "pedia não por si, mas pelas pessoas que sofriam mais do que ela". A história da suposta santidade de "Mariazinha" Penna reside em seu exemplo perante o enfrentamento de um câncer. Abelin tornou-se ciente da história envolvendo Mariazinha Penna em 1960, quando então residia em Passo Fundo, pois, mesmo poucos anos depois da morte da mesma, "comentavam que era intensa a romaria de pessoas à sua sepultura, pedindo ou agradecendo intercessões".

Ao estudar a história das crençasnas "santas" "Mariazinha" Penna e Maria Elizabeth de Oliveira se objetiva também entender o lugar que estas expressões culturais do patrimônio de uma parcela da sociedade ocupam na atualidade. Nesse contexto, o presente estudo justifica-se na medida em que enfatiza o estudo dos estilos de fazer e lidar com as vicissitudes que fazem parte do cotidiano, investigando como o Brasil realmente é.

Ao analisarmos estas duas devoções e as memórias dos devotos sobre as mesmas buscamos compreender diferentes lógicas que estão em jogo na ação e representação de diversos grupos sociais. Ademais ainda precisamos realocá-los no interior dos processos sociais dentro dos quais estas devoções funcionam e ganham sentido, podendo assim, compreender como determinados locais e tempo surgiram e se desenvolveram tais devoções. Outro fator a se levar em consideração no estudo das devoções e dos rituais contemporâneos diz respeito à inserção da ideia de mercado. Nesse contexto,

\begin{abstract}
A racionalização do sagrado se realiza pela sua mercantilização: ou adeptos se tornam clientes que escolhem os produtos segundo suas necessidades; as religiões, colocadas em situação concorrencial, desenvolvem práticas racionais de gestão eficiente dos cultos, esvaziam de sacralidade suas mensagens e adotam técnicas de convencimento do tipo publicitário (MONTEIRO, 1994, p. 85).
\end{abstract}

Algumas das perspectivas de leitura da comercialização das e nas devoções apresentadas consistem na investigação dos pontos e dos bens simbólicos que

${ }^{2}$ Contidos na biografia e anualmente nos jornas de Santa Maria - A Razão e Diário de Santa Maria. 
fomentam as devoções hoje. As peregrinações aos túmulos como evento com um enfoque para estes bens de mercado que auxiliam na conquista do fiel e que são práticas já largamente utilizadas pela Igreja Católica, entretanto, como se percebeu o comércio da fé tem sido também amplamente utilizado por outras esferas, assim como o Poder Público Municipal, entre outros, o que em nossa opinião caracteriza as práticas religiosas atuaistambém como possuidoras de um caráter multifuncional do turismo religioso. ${ }^{3}$

\section{Do campo do religioso para o profano: o comércio da fé}

O turismo religioso ocorre quando a festividade, o lazer e o consumismo transcendem o campo do sagrado, da espiritualidade, encontrando-se na junção de vários elementos, como a cultura popular, a urbana e a religiosa, presentes todos eles em apenas um local. Para Andrade, o conjunto de atividades com a utilização parcial ou total de equipamento e a realização de visitas e receptivos que expressam sentimentos místicos ou suscitam a fé, a esperança e a caridade aos crentes ou pessoas vinculadas a religiões, denomina-se como turismo religioso (ANDRADE, 2000, p. 77). Dito isso, entendese que a conexão turismo-religiosidade é nodal para refletir-se sobre algumas das mudanças culturais mais amplas da sociedade. Para Steil (1978), o significado do turismo religioso se dá quando o sagrado migra como estrutura para o cotidiano, para as atividades festivas, o consumo, o lazer, quando, enfim, os turistas passam a vivenciar esses eventos, como as páscoas e os natais, não mais somente vinculados às tradições religiosas, mas como uma experiência singular, espiritual e ao mesmo tempo consumista. Diversos grupos de sujeitos frequentam os mesmos espaços já que celebrações dessa natureza incitam os mais diferentes públicos.

A simples atração pelo festejo gera uma demanda para a localidade em que ocorre, seja em uma área urbana ou rural, pois também será conhecida e lembrada pelo evento (RIBEIRO, 2004, p. 48). Sendo assim, o turismo religioso funcionará ou não como uma forma de estímulo à construção de uma identificação positiva da comunidade, configurando-se como uma fonte de autoestima para ela. Nesse percurso, pretendese perceber que a forma de relacionar-se que visitantes e habitantes, bem como romeiros e turistas desenvolvem com o 'bem’ cultural, no caso sua devoção, é fundamentalmente diverso. Para que a memória em determinada santa continue existindo, muitas vezes necessita -se de lugares de memória, assim, no caso das devoções a Maria Elizabeth e "Mariazinha" Penna esses locais são seus próprios jazigos, visto que estes os locais de peregrinação dos devotos. A respeito da utilização do patrimônio nas construções históricas, Gonçalves pensa que:

\footnotetext{
A luz dessa categoria (patrimônio imaterial), aquelas instituições ritos e objetos podem ser percebidos simultaneamente em sua universalidade e em sua especificidade; reconhecidos ao mesmo tempo como necessários e contingentes; adquiridos (ou construidas reproduzidas no tempo presente) e ao mesmo tempo herdados (recebidos dos antepassados, de divindades, etc.); simultaneamente mate-
}

\footnotetext{
${ }^{3}$ No Brasil, a obrigatoriedade histórica de uma religião oficial durante a colônia até o fim do império foi o fator primordial para manutenção dos valores católicos em toda extensão do território brasileiro. Em países de formação religiosa católica, a dinâmica que caracterizou a sua formação tem características que os fizeram diferentes entre si, apesar de terem as origens comuns na Igreja Católica Apostólica Romana. Essas diferenças foram construídas inicialmente a partir da instalação de Ordens Religiosas (Salesianos, Franciscanos, Beneditinos, entre outras), que fizeram sedimentar este ou aquele aspecto da religiosidade local ou regional, os quais com o passar dos anos e séculos, tornaram-se características culturais das comunidades. O turismo religioso, portanto é uma das modalidades do turismo brasileiro que mais tem se desenvolvido devido a vários fatores, dentre os quais se pode citar: a formação histórica do povo brasileiro, ligada diretamente à Igreja Católica, e a diversidade de organizações religiosas católicas que se estabeleceram no país nestes 500 anos. Nas principais cidades históricas do Brasil, os principais atrativos são as igrejas construídas em diversas épocas da colônia e do império, construções que estão ligadas à história da população local em cada cidade (Cf. http://br.geocities.com/geoturuff/ turismoreligioso.html)
} 
riais e imateriais; objetivos e subjetivos: reunindo corpo e alma; ligados ao passado, ao presente ao futuro; próximos, ao mesmo tempo que distantes; assumindo tantas formas sociais quanto formas textuais (por exemplo, nas etnografias e nos ensaios em que foram representados). $O$ sentido fundamental dos 'patrimônios' consiste talvez em sua natureza total e em sua função eminentemente mediadora (GONÇALVES, 2005, p. 30).

Um local de romaria vai se transformando em receptivo turístico na medida em que o processo mais amplo de modernização avança, criando condições, serviços e representações sociais e simbólicas do turismo que lhe deem sustentação. A visita ao templo, ao pagar a promessa, a viagem para a realização de um milagre, de devoção transformam-se em turismo. Assim, participamos do pensamento de Guidolin; Winter; Zanotto quando analisam as Romarias de Passo Fundo/RS, pois percebemos que o mesmo ocorre em Santa Maria, pois o crescimento da romaria do seu início até os dias de hoje é evidente, transformando essa manifestação religiosa em um evento turístico-religioso. Em que as mudanças fazem parte de um processo contínuo, que é necessário para a existência e o sucesso da Romaria (GUIDOLIN; WINTER; ZANOTTO, 2011, p. 206207).

No caso de Santa Maria e a devoção a "Mariazinha" Penna, além da fé do povo, que na verdade encaramos como o maior bem, nos últimos vinte e sete anos o Poder Público Municipal corroborou a fé local e auxiliou no processo de santificação dando o nome de "Mariazinha" a uma Rua no Bairro Traquedo Neves, por meio da Lei número 3028/88, de 21 de setembro de 1988 e por meio do então prefeito José HaidarFarret e a uma Praça no Bairro Passo da Ferreira, além do fato de que, ao lado de seu túmulo a família conseguiu comprar um terreno a fim de colocar as várias placas de agradecimento por graças alcançadas, assim, como, no Bairro Camobi foi construída uma er- mida para a mesma, visto que, é o Bairro de seu nascimento. Nesse contexto para Carneiro, o turismo, como um campo dinâmico, apresenta sempre novos desafios, resultados das formas de organização do trabalho, da possibilidade de novas experiências no contato com a realidade, associadas ao desenvolvimento das tecnologias de comunicação, bem como da emergência de preocupações sociais e ambientais (CARNEIRO, 2004, p. 75-78). Dessa forma, o turismo afirma-se não só como fenômeno de consumo, mas também como fenômeno de produção. Essa maneira de conceituá-lo permite incorporar ao debate tanto a noção de produto turístico como a figura dos agentes produtores.

Até mesmo o sentido etimológico da palavra peregrino remete ao estrangeiro, aquele que vem de fora, que é de outro lugar. E esse é um dos enfoques possíveis sobre o comportamento turístico, pois se assenta na ideia de que o turismo poderia ser lido como uma atualização da peregrinação, ao qual se acarretam sentidos e valores que em outros momentos foram rechaçados de serem vividos nesta experiência religiosa. As peregrinações nas sociedades contemporâneas têm influenciado expressivamente um dos mais significativos setores da vida social, afetando diretamente a área do turismo.

Assumindo o pressuposto de que alguns elementos da peregrinação foram absorvidos pelo turismo moderno, também o é que o turismo parece ter canalizado parcela da mística da peregrinação para si. Neste sentido, pode-se influir que boa parcela das experiências de peregrinação é permeada por um sofisticado sistema de turismo que lhe fornece suporte material e visibilidade, ao mesmo tempo em que muitas atividades turísticas têm como motivação elementos religiosos (SILVA, 2010, p. 67). No caso de Maria Elizabeth, a comercialização de sua imagem corre a favor da divulgação da própria cidade, visto que, também é motivo e 
atrativo de visitantes e visitação. Além disso, no catálogo de visitação ao Cemitério Vera Cruz, em Passo Fundo o túmulo da "santa" popular encontra-se em evidência, além do fato de que é o primeiro jazigo quando se entra no referido cemitério. Não obstante, existe em frente ao cemitério onde Maria Elizabeth se encontra sepultada, uma floricultura de propriedade de sua família, local em que os devotos, visitantes ou turistas podem adquirir objetos sagrados/profanos comercializados como lembranças da "santinha" local. Entre estes objetos podemos destacar:

\section{MARIA ELIZ,ABETH, PROTEGEIME - P, FUNDO / TSS}

Imagem 1-“Fitinha" de pulso com proteção de Maria Elizabeth.

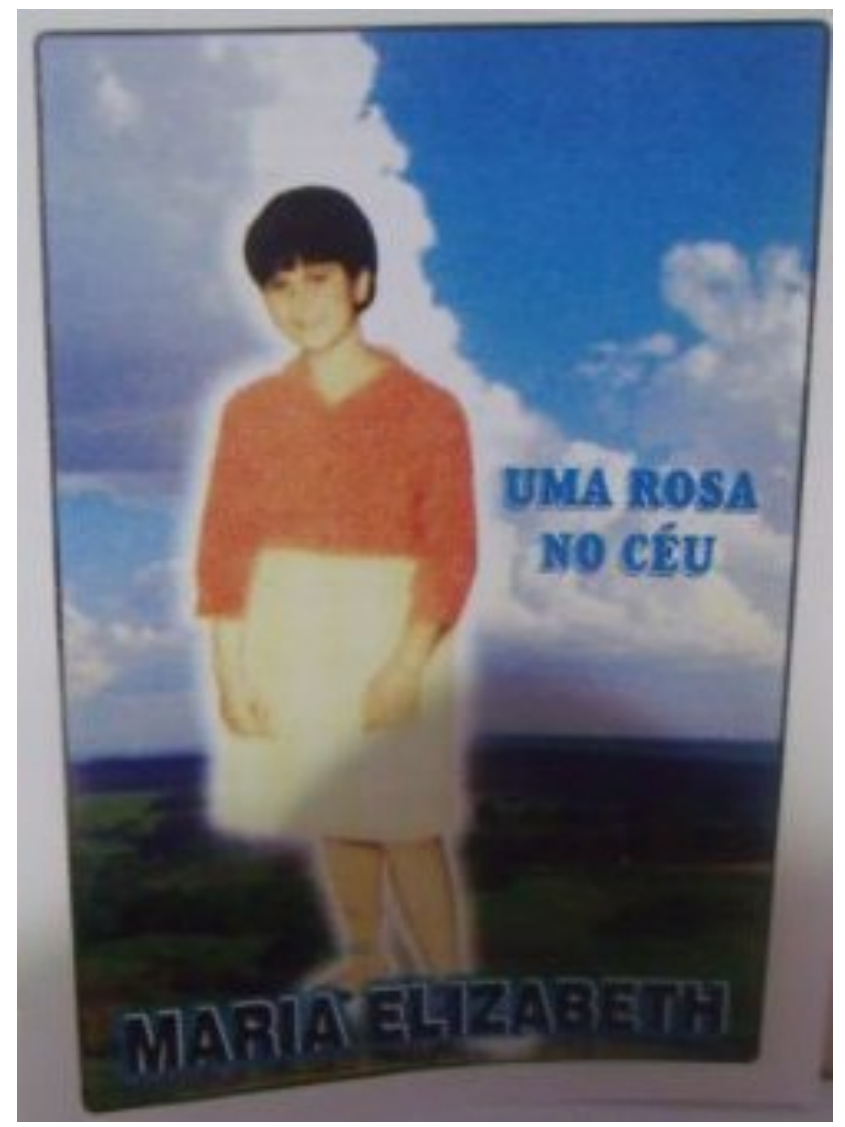

Imagem 2-"santinho" com reprodução da imagem de Maria Elizabeth.

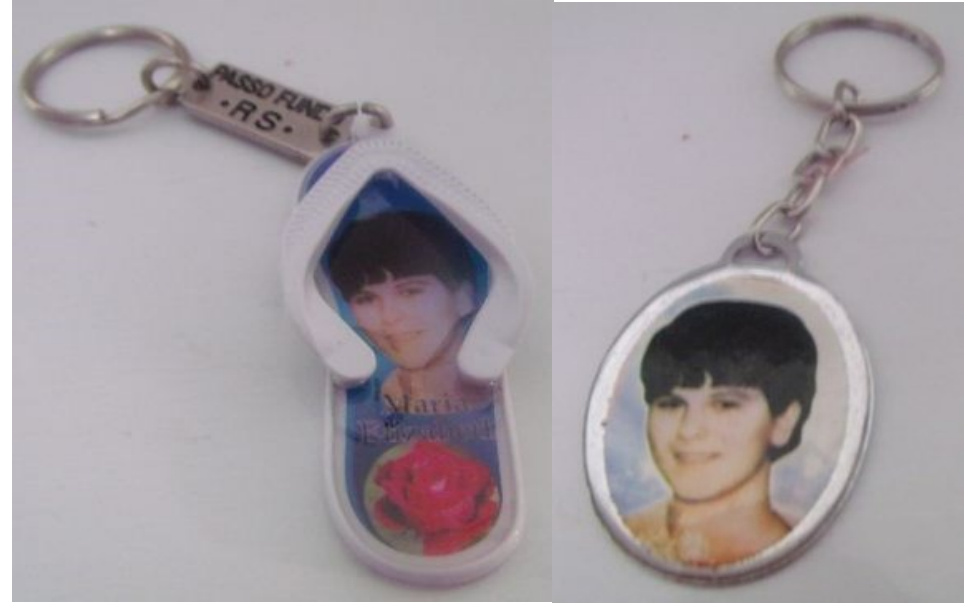

Imagens 3 e 4-Chaveiros com imagem de Maria Elizabeth.

As transformações ocorridas no transcorrer dos anos de devoção e peregrinação aos túmulos fazem das mesmas não só um patrimônio imaterial, mas um lugar de atrativo turístico que propicia diversificação de negócios, em que os transportes se multiplicam, as empresas de ônibus e áreas criam e revitalizam novas e antigas rotas, surgem mais empregos, o comércio cresce, enfim, uma série de mudanças passa a ocorrer e que podem significar a revitalização da economia local de muitos municípios de pequeno e médio porte no Brasil (SILVEIRA, 2007). Por outro lado, para Silveira, o pluralismo religioso intensificou-se a partir das décadas de 1980 e 1990, tendo em vista que nesse período a modernização industrial e a urbanização explodiram no Brasil, além de caracterizar-se como a década da construção do mercado turístico nacional. O governo brasileiro, por meio da EMBRATUR ${ }^{4}$, investiu em programas de incentivo ao turismo e emprestou dinheiro para a construção de extensas redes hoteleiras e, assim, as agências de turismo espalham-se.

Segundo a Fundação Getúlio Vargas, em pesquisa feita no ano 2007, o Brasil é um dos países com maior número de católicos do mundo, com uma população que se identifica por vivenciar diversificada religio-

\footnotetext{
${ }^{4}$ A EMBRATUR é a autarquia especial do Ministério do Turismo responsável pela execução da Política Nacional de Turismo no que diz respeito a promoção, marketing e apoio à comercialização dos destinos, serviços e produtos turísticos brasileiros no mercado internacional. Trabalha pela geração de desenvolvimento social e econômico para o País, por meio da ampliação do fluxo turístico internacional nos destinos nacionais. Disponível em: < http:// www.turismo.gov.br/turismo/o_ministerio/embratur/>. Acesso em: 20 nov. 2013.
} 
sidade popular. A partir desse dado é possível declarar que o turismo religioso pode vir a ser uma área com grande potencial a desenvolver-se, o que só ocorrerá se for bem planejado e organizado. Sendo assim, pode-se dizer que diversas manifestações religiosas, que fazem parte da cultura, vêm se transformando em verdadeiros 'espetáculos', mobilizando para si a cada ano milhares e milhares de pessoas.

Cada grupo de pessoas possui suas próprias motivações - diferentes e pessoais - para participar de uma peregrinação: agradecer os pedidos que já foram alcançados; pagar promessas; fazer promessas; manter a tradição da família; lazer; comércio; política; superar obstáculos; entre outros. Essa demonstração sociocultural divide espaço com a participação de sujeitos procedentes de diferentes classes econômicas, de crianças, de jovens, de idosos, de mulheres, de homens, mostrando a diversidade do público fiel.

Dessa forma, pode-se inferir que as possibilidades de experimentação turística de determinada estrutura da sociedade se devem a fatores como o seu potencial político-econômico, a singularidade do ritual e de sua divulgação consistente e sistemática, por meio da imagem que se pretende projetar. Quanto às manifestações de cunho cultural-religioso, como no caso das devoções “as Marias”, a sua concepção está centrada nos devotos e nos grupos de agentes sociais que participam dessa esfera ora sacra, ora profana. Nesse contexto, para Prats (1997)' o patrimônio como recurso turístico pode ser sistematizado de três formas distintas: a) $\mathrm{O}$ patrimônio pode se constituir em um produto turístico per se capaz de integrar junto à oferta hoteleira, um motivo de compra autônoma; b) O patrimônio pode ser apresentado como 'associado' a um produto turístico integrado (pacote de viagem), sendo parte integrante do produto e; c) O patrimônio pode se construir em um valor agregado para destinos turísticos que não possu- em no patrimônio o atrativo principal ou o motivo de compra. Das inúmeras manifestações religiosas existentes, ao menos três tipos podem tornar-se objeto turístico: as do patrimônio arquitetônico (igrejas barrocas, templos budistas, protestantes, etc.), as do ritual (Semana Santa, ritos celebrativos ou de comemoração, etc.) e as de eventos (festas religiosas, festivais de música, etc).

Para ser considerado como um produto turístico, os bens de devoção e seus locais de culto foram analisados como basilares para atrair para os municípios de Passo Fundo e Santa Maria não somente os romeiros e/ ou peregrinos, mas também outros grupos sociais. A partir daí os eventos começam a sofrer alterações com um possível redimensionamento de seus espaços e de seus serviços oferecidos antes, durante e depois da celebração. Tendo em vista que, no momento em que as devoções passam a interessar a agentes privados/ públicos que normatizam sua comercialização, ela vai passando a compor conjuntamente a outros eventos/ elementos um produto socioturístico em sua região de abrangência.

A tendência do campo cultural-religioso contemporâneo caracteriza-se por um crescente pluralismo que entendemos estar se deixando influenciar pela mercantilização das várias formas do sagrado. O campo religioso bem como o político e o cultural é altamente competitivo internamente assim como o mercado capitalista. $\mathrm{O}$ fenômeno religioso tem se mostrado bastante ambíguo e extremamente marcado por visões contraditórias, graças a sua (relativa) autonomia.

As sociedades influenciadas pelo capitalismo adaptaram as religiões as suas ideologias em vez de reprimi-las. O capitalismo e sua ideologia foi mais hábil que os comunistas em instrumentalizar amplos setores das religiões para fins de justificar o status quo. [...] As Igrejas, em grande parte, suspiraram aliviadas com o ressurgimento religioso, mas logo se 
deram conta, frustradas, que o que voltou veio transformado por um mergulho no 'novo mundo neoliberal', de onde saiu com um compromisso com o aqui e agora, sem a dimensão utópica e sem céus e infernos no além morte (BOBSIN, 2014, p. 5).

Nesse contexto, podemos entender que o que passa a ter valor na sociedade contemporânea e ser dominante é o presentísmo 5 e, assim, o que se pode com- prar, como uma experiência turística, por exemplo. Além disso, o assistir ao evento sem uma relação mais íntima de apropriação do patrimônio pelo turista nãodevoto nos traz mais uma das perspectivas das contemporâneas relações entre devotos-turistas-romeiros. A mística da peregrinação hoje nos demonstra "uma reação que traz a religião do espaço privado para o público".

\section{Referências bibliográficas}

ABELIN, Leyda Tubino. Mariazinha Penna: a predestinada. Porto Alegre: Ed. Nova Dimensão, 1988.

ACOSTA, Alexandre Chies. Minha experiência de Deus e os sinais de Maria Elizabeth de Oliveira. Bento Gonçalves, 2009.

ANDRADE, José Vicente. Turismo Fundamentos e Dimensões. São Paulo: Ática, 2000.

BARBOSA, Uma estrela no céu - Maria Elizabeth de Oliveira. 7a , 9a (versão de bolso) 34. ed., EST, Porto Alegre, 2014.

BOBSIN, Oneide. Contemporaneidade e religiões. Revista Textual, vol. 1, nº 19, maio de 2014.

CARNEIRO, Sandra Maria Corrêa de Sá. Novas peregrinações Brasileiras e suas interfaces com o turismo. Ciências Sociais e Religião. Porto Alegre, ano 6, n. 6, out., 2004.

FABIANI, Márcia. Maria Elizabeth de Oliveira: a construção do imaginário, da devoção e da santidade. Passo Fundo. Dissertação (Mestrado). Programa de Pós-Graduação em História, Universidade de Passo Fundo, 2006.

GUIDOLIN, Camila; WINTER, Murilo D.; ZANOTTO, Gizele. Plasticidade ritual: um estudo de caso das romarias de Passo Fundo. In: BASTITELLA, Alessandro (Org.). Patrimônio, memória e poder: reflexões sobre o patrimônio histórico-cultural de Passo Fundo (RS). Passo Fundo: Méritos, 2011, p.206-207.

GONÇALVES, José Reginaldo. Ressonância, Materialidade e Subjetividade: as culturas como patrimônios. Horizontes Antropológicos, Porto Alegre, ano 11, jan./jun., 2005.

MONTERO, Paula. Magia, Racionalidade, Sujeitos Políticos. Portal das Ciências Sociais Brasileiras. RBCS, n.26, Ano IX, Outubro de 1994. Disponível em <http://www.anpocs.org/portal/index.php? option $=$ com_content\&view $=$ article $\&$ id $=211$ :rbcs-26\&catid $=69:$ rbcs\&Itemid $=399>$

MORENNO, Pablo. Maria Elizabeth de Oliveira. 150 Momentos mais importantes da História de Passo Fundo, 1994, p. 318-319.

PRATS, Llorenç. Antropologia y patrimônio. Barcelona: Arial, 1997.

RIBEIRO, Marcelo. Festas Populares e turismo cultural - inserir e valorizar ou esquecer; Passos: Revista de turismo y patrimônio cultural, v. 2, 2004.

SILVA, Alexandra BEGUERISTAIN. As Práticas Humanizadoras de hospitalidade nos eventos programados em Santa Maria - estudo de caso: Romaria de Nossa Senhora Medianeira. (Monografia) Trabalho Final de especialização em Gestão do Turismo Sustentável, UNIFRA, 2010.

SILVEIRA, Emerson Sena da. Por uma sociologia do Turismo. Porto Alegre: Zouk, 2007.

STEIL, Carlos Alberto. Peregrinação e turismo: o Natal em Gramado e Canela. Anais do XXII Reunião Anual de ANPOCS, 1998.

ZANELLA, Noely da Costa. Uma luz em meu caminho - Maria Elizabeth de Oliveira. 3. ed. Esmeralda, 1997.

Submissão: $22 / 05 / 2016$

Aceite: $25 / 10 / 2016$

\footnotetext{
${ }^{5}$ Tese que diz que o que tem valor é o hoje e o agora.
} 